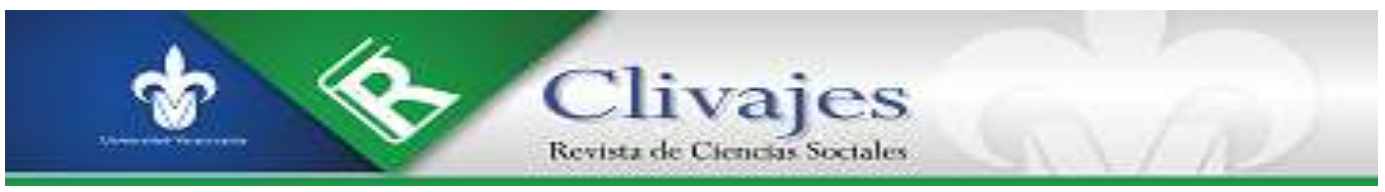

Marian Mndoza Gómez

mrnrhs@hotmail.com

Maestría en Educación, Universidad Pedagógica Veracruzana

EDUCACIÓN, POLÍTICAS PÚBLICAS Y CULTURA

DOI: https://doi.org/10.25009/clivajes-rcs.v0i14.2669

Clivajes. Revista de Ciencias Sociales. Año VII, número 14, julio-diciembre 2020, pp. 262-267

https://clivajes.uv.mx/index.php/Clivajes/article/view/2669/4483

Instituto de Investigaciones Histórico-Sociales, Universidad Veracruzana

Clivajes. Revista de Ciencias Sociales/ISSN: 2395-9495/IIH-S, UV/Xalapa, Veracruz, México

Recibido: $10 / 10 / 2019$

Aceptado: 25/10/2019

Clivajes. Revista de Ciencias Sociales (ISSN: 2395-9495), Año VII, Núm. 14, julio-diciembre, 2020

Instituto de Investigaciones Histórico-Sociales, Universidad Veracruzana, México 


\section{Educación, políticas públicas y cultura}

\author{
Marian Mendoza Gómez*
}

\begin{abstract}
Resumen
Pedro Flores Crespo (2017) invita a reflexionar, evaluar y repensar la problemática educativa vigente, en un libro provocador, editado por CREFAL/UAQ, que interpela al lector con respecto a sus concepciones y posiciones al respecto. Imposible no cuestionarse sobre el sentido de la educación en el contexto nacional y adoptar una actitud crítica y propositiva.
\end{abstract}

Palabras clave: Educación Políticas educativas, Arte, Cultura, Actores

\section{Education, public policies and culture}

\section{Summary}

Pedro Flores Crespo (2017) invites us to reflect, evaluate and rethink the current educational problem, in a provocative book, edited by CREFAL/UAQ, which questions the reader with respect to his / her conceptions and positions in this regard. It is impossible not to question the meaning of education in the national context and adopt a critical and purposeful attitude.

Keywords: Education, educational policies, art, culture, actors

\section{Éducation, politiques publiques et culture}

Résumé

Pedro Flores Crespo (2017) invite à réfléchir, évaluer et repenser sur la problématique éducative en vigueur, dans un livre provocateur, édité par CREFAL/UAQ, qui interpelle le lecteur en ce qui concerne ses conceptions dans le contexte national et adopter une attitude critique et pro positive.

Mots clés : Education, Politiques éducatives, Art, Culture, Acteurs

* Docente en Maestría en Educación de la Universidad Pedagógica Veracruzana; estudiante del Doctorado en Historia y Estudios Regionales del Instituto de Investigaciones Histórico-Sociales de la Universidad Veracruzana, México. Contacto: mrnrhs@hotmail.com.

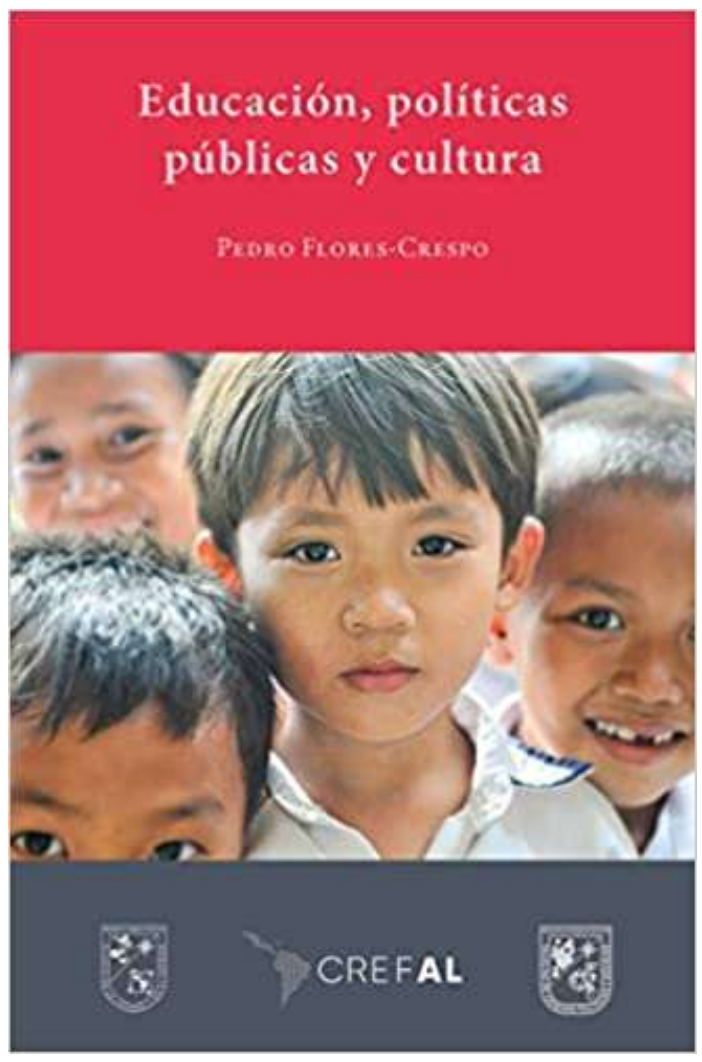

Asumir una posición crítica sobre las formas en que tanto la educación como los elementos que la rodean son percibidos constituye una necesidad, que recae en el hecho de que los tiempos y los espacios son tan dinámicos, como los individuos y las sociedades a las que pertenecen; por lo tanto, los deseos, las intenciones, los objetivos y las necesidades son también cambiantes. En sentido estricto, esto se evidencia a partir de los dispositivos de que se ha valido la educación para orientar lo social; en la actualidad, hablamos de políticas públicas.

Hay que subrayar que las decisiones tomadas por los individuos sobre lo educativo tienen consecuencias 
significativas que influyen en todas las esferas de la vida cotidiana y perduran en la historia. Sin duda, para bien o para mal, la educación es el elemento clave para la transformación del devenir social.

$\mathrm{Al}$ respecto, en Educación, políticas públicas y cultura, publicación del Centro de Cooperación Regional para la Educación de Adultos en América Latina y el Caribe (CREFAL) y la Universidad Autónoma de Querétaro (UAQ), Pedro Flores Crespo (2017) nos invita a emprender este ejercicio reflexivo: repensar y evaluar críticamente los temas implicados en el ámbito educativo. Es un libro provocador, en el sentido de que, tras la lectura, es imposible no cuestionarse, desde los propios posicionamientos y contextos, sobre el sentido de la educación, y abandonar las actitudes pasivas:

Cultivando la idea de que la crítica, el ambiente ideológicamente plural que vivimos, la agitación política y social que posibilita nuestra frágil democracia, así como la relativa libertad de prensa y expresión trabajen a favor de la educación (p. 12).

Esta revisión permite a los lectores autoevaluarse como posibles "agentes de cambio". Si bien la obra reúne artículos de opinión que dan cuenta de la experiencia del autor en el sector académico y político, la divulgación de sus ideas también ha sido posible en otros espacios públicos que fomentan la participación y el debate, sin perder, como es consigna en este libro, la objetividad e imparcialidad.

Ahora bien, dado que se trata de una compilación de artículos, el análisis de cada uno de los temas propuestos en la obra resulta limitado. Sin embargo, el hecho de haberlos manifestado, abierta y explícitamente, contribuye a que no pasen desapercibidos para los especialistas en los campos educativo y de políticas públicas, a quiénes les compete atender los fenómenos y problemáticas que pone a revisión. En otras palabras, el análisis de los temas queda restringido en la obra, pero, al mismo tiempo, abre la posibilidad de estudiarlos o considerarlos como líneas de investigación o acción en los marcos gubernamentales.

Teóricamente, pareciera que el autor promueve un enfoque sociopolítico en el campo de la educación, cuyos cimientos se hallan, principalmente, en la noción de política educativa. No obstante, este enfoque se articula con otros, como el enfoque cultural, el económico, el filosófico e incluso el artístico, que se entrelazan entre sí para dar una visión otra de lo que acontece en la educación mexicana del siglo XXI, desde el nivel básico hasta el superior, promoviendo la interdisciplinariedad en el campo, más allá de aspectos meramente institucionales y gubernamentales. 
Otro aspecto a detallar es que, aun cuando se preocupa por explicar la experiencia educativa de México, el autor no se detiene a considerar otras realidades al exterior, a pesar de que los problemas que subyacen en la educación no son exclusivos de una sola nación, sino que resultan similares e igualmente complejos en cualquier otra parte del mundo.

En cuanto a su estructura, Educación, políticas públicas y cultura, de Flores Crespo, está organizado en Introducción, seis capítulos, y un Epílogo de Salvador Ruiz de Chávez Ochoa, ex rector de la Facultad de Contaduría y Administración de la Universidad Nacional Autónoma de México (UNAM).

El primer capítulo, "Análisis de políticas públicas", aborda distintos fenómenos que rodean, específicamente, al campo de la investigación de las políticas educativas: la gobernanza, los think tank en la educación, la influencia de modelos internacionales sobre los modelos nacionales y locales, por mencionar algunos. Además, cuestiona a los actores que participan, activa y reiteradamente, en el proceso de elaboración de las políticas educativas en México; algunos con escasa preparación o una perspectiva limitada a la objetividad, mientras que otros, igualmente importantes, son excluidos: menciona, por ejemplo, el caso de los estudiantes universitarios, es decir, los beneficiarios de o afectados por esas políticas. Las problemáticas de todo proceso de implementación de políticas públicas, independientemente de su carácter educativo, tienen su raíz en el momento de su diseño, con diversas implicaciones a posteriori.

Flores Crespo señala, por otro lado, que en México hay una tendencia muy fuerte a la personalización de las políticas educativas, las cuales suelen atribuirse a un funcionario o una administración de gobierno federal, estatal o local; sobre ello, en otro apartado pone como ejemplo el papel del exsecretario de Educación, Fernando Solana, lo cual sugiere dos cosas: 1) que si bien hay individuos que demandan una mayor participación y gracias a los cuales se han creado espacios para el diálogo y el debate acerca de los temas que atañen a la educación, sólo unos pocos siguen tomando las decisiones sobre la agenda educativa; 2) que las hechuras de políticas públicas en educación, reflejo del autoritarismo o el paternalismo, han sido una tradición política e histórica. Para superar esta concepción, propone una cultura de gobierno plural y abierta (2017).

Como propuesta metodológica, el autor nos invita a recurrir a los estudios de política comparada que se han desarrollado en distintos niveles y momentos. Tales estudios no sólo se concentran en las implicaciones prácticas 
o políticas de las políticas públicas, sino que también recurren a la teoría para comprender cómo se construye una política educativa, entendida como:

Un curso de acciones-implícitas y explicitas- que surge primordialmente desde el gobierno, pero que es recreado de manera constante por los diversos actores sociales y políticos. Esto con el propósito de cumplir con las finalidades que el Estado se va fijando (Flores Crespo, 2017, p. 30).

En "Desigualdad y justicia social", segundo capítulo de la obra, Flores Crespo demuestra numerosas contradicciones y complejidades de las tesis, los principios e ideales manifiestos en las políticas y los programas educativos; menciona, por ejemplo, algunos de los problemas derivados de la privatización de las escuelas en México, donde, de por sí, las brechas sociales son muy amplias. De acuerdo con el último censo del CONEVAL (2018), que va de 2008 a 2018, el $65.6 \%$ de la población es pobre; ${ }^{1}$ de ahí que, según el autor, esta población tenga dificultades para acceder a diversos servicios y sea vulnerable en cuanto al respeto de sus derechos, uno de los cuales es precisamente el acceso a la educación. A modo de contradicción, en este apartado el autor señala que algunos

\footnotetext{
${ }^{1}$ Coneval (2018). Pobreza en México. Recuperado de https:/ / bit.ly/3sUpjGd.
}

políticos defensores del principio de educación "laica, gratuita y obligatoria", tal como está marcado en la Constitución mexicana, desde 1917, mantienen a sus hijos en escuelas privadas.

Flores Crespo nos recuerda que este tipo de acciones y formas de pensamiento, las cuales se han vuelto hegemónicas en las políticas públicas, plantean no sólo injusticia, sino también inequidad, segregación e incluso discriminación; ejemplos de ello son que la meritocracia "puede tener un efecto en el proceso de alcanzar una determinada posición social" (p. 70), ajena al propio origen, y que las políticas educativas sólo estén orientadas a ciertos sectores de la población.

En el tercer capítulo, "Ciudadanía y democracia”, el autor expone algunas de las responsabilidades de la educación en la construcción de ciudadanía y el fomento de la participación ciudadana en ámbitos fuera de los espacios escolares; muestra, asimismo, cómo ciertos ciudadanos participan y aportan ideas y propuestas para orientar lo educativo; en este sentido, por un lado aborda el tema de las pluralidades y, por otro, el intento de actores educativos por alzar un proyecto hegemónico; tal es el caso de los sindicatos magisteriales de este país, que siempre han estado íntimamente vinculados a la esfera política $y$ gubernamental. 
En "Universidad crítica", cuarto capítulo de Educación, políticas públicas y cultura, Flores Crespo muestra algunos claroscuros, principios y proezas de las universidades públicas en México y el exterior. En el caso de las universidades mexicanas, estos espacios educativos con sus propias dinámicas- se constituyen como "microespacios" de lucha y consenso en pro de la autonomía, la participación, el aumento presupuestal, el acceso a la educación y el multiculturalismo. Cabe precisar que cuando el autor habla de la "critica" en la educación superior alude no sólo a los procesos al interior de las universidades, sino también al tipo de análisis que él mismo realiza.

En el quinto capítulo, "Arte y cultura”, Flores Crespo plantea una pregunta de fondo: ¿cómo se relaciona la educación con el arte y la cultura? Tal vez se podría considerar un cuestionamiento muy complejo, abstracto, incluso que se trata de un debate añejo - como la falsa dicotomía entre arte y ciencia-, pero interesante por la manera en la que el arte incide en la educación, y no necesariamente al revés, por ejemplo a través de la poesía o una canción de Juan Gabriel. Además, el autor demuestra que así como el arte, los medios de comunicación también influyen en la educación, en particular los programas televisivos.
El sexto y último capítulo del libro, titulado "Ciencias sociales y el papel de los intelectuales", constituyen un recordatorio sobre la importancia de los intelectuales y su incidencia de todas las esferas sociales. Desde su formación, hasta su desempeño en el campo profesional, en torno a ellos hay intereses, problemáticas, políticas de fondo, sobre todo en un contexto donde cada vez se cuenta con más intelectuales con postgrados y se deifica la meritocracia -como menciona el autor en otros capítulos-, perceptible a través de premios, bonos, privilegios.

Educación, políticas públicas y cultura recupera una selección muy completa de temáticas que trascienden en espacio y tiempo, y siembran impaciencia en el lector: impaciencia por saber, conocer, indagar más. La claridad y honestidad con la que el autor se expresa permite que, más allá del ámbito académico, otros públicos puedan disfrutar de su lectura: Flores Crespo, P. (2017). Educación, políticas públicas y cultura. México: CREFAL, UAQ. 